\title{
Tipps und Tricks: \\ Bestimmen der Länge von Schanz-Schrauben
}

\author{
Dankward Höntzsch
}

Wenn man Schwierigkeiten hat, die richtige Länge von Schanz-Schrauben abzuschätzen, hilft folgendes Vorgehen:

Man bohrt vor. Wenn die Gegenkortikalis gerade durchlaufen ist, wird der Bohrer nicht sofort zurückgezogen, sondern es wird kurz gewartet. Dann kann man mit einem Stift, der zur Markierung auf der Haut verwendet wird, am Bohrer eine Markierung anzeichnen. Der Bohrer wird dann zurückgezogen und man kann die Länge der Schanz-Schraube von der Spitze bis zur Markierung bestimmen.

Eine andere Möglichkeit ist, dass man den Bohrer entweder mit einem Ring von einem Drainageüberleitungssystem bestückt oder aus der Gummihalterung für Schanz-Schrauben (Abb.) einen elastischen Ring macht. Bevor man mit dem Bohren anfängt, stülpt man entweder den kleinen Plastikring des Drainageschlauchs oder das mit Loch versehene Gummiteil über den Bohrer. Wenn der Bohrer die Gegenkortikalis gerade durchlaufen hat, wird dann die Markierung auf die gewünschte Länge geschoben und der Bohrer zurückgezogen. So kann ebenfalls die Länge von der Bogenspitze bis zur Markierung bestimmt werden (Abb.).

Bitte senden Sie Ihre Tipps und Tricks ein, damit dies ein lebendiger Austausch wird und wir voneinander lernen können. Bitte an: op-journal@thieme.de oder Georg Thieme Verlag KG, OP-journal, z. Hd. Frau Stickel, Rüdigerstraße 14, 70469 Stuttgart.

\section{Prof. Dr. med. Dankward Höntzsch}

\section{Cranachweg 9 \\ 72076 Tübingen}

hoentzsch@t-online.de
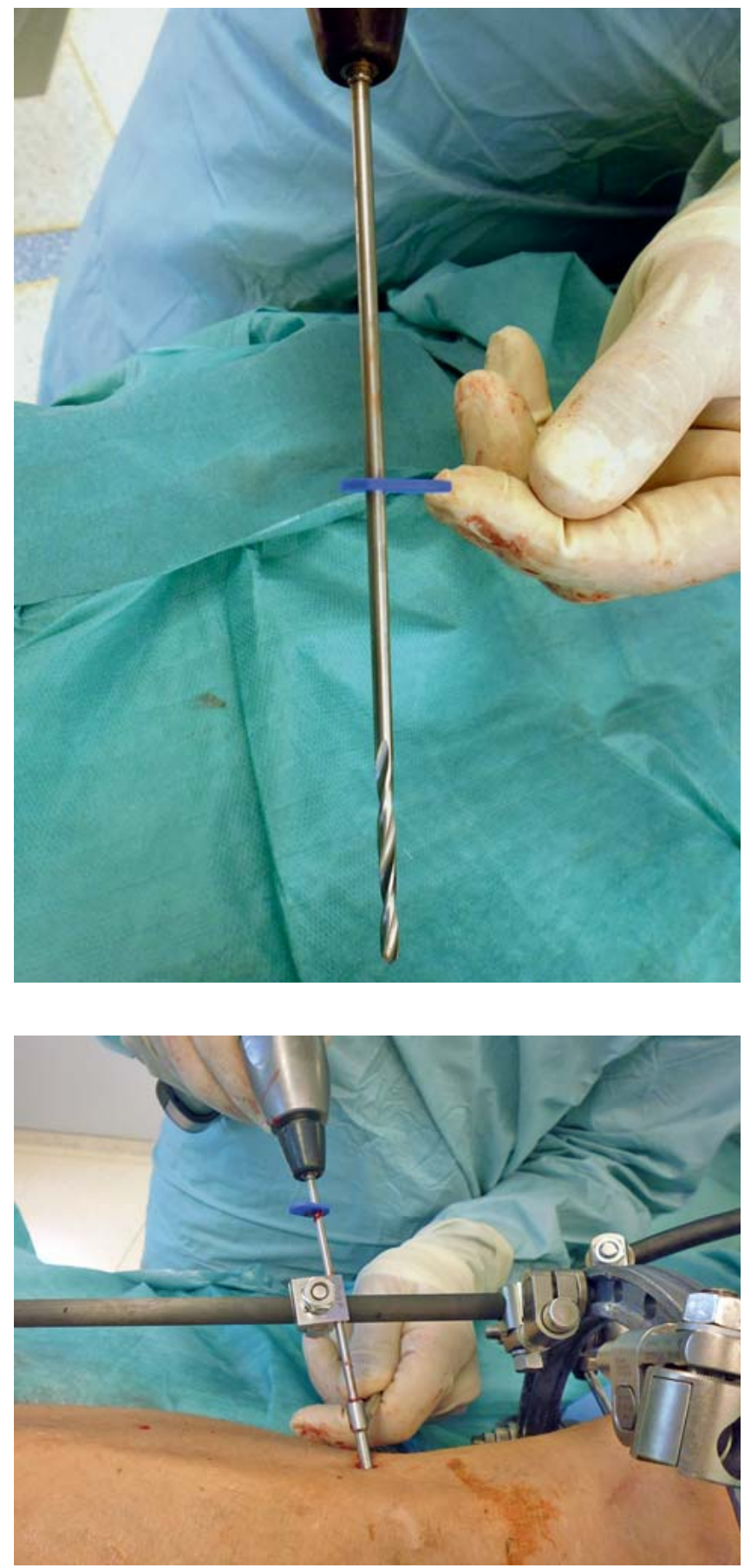